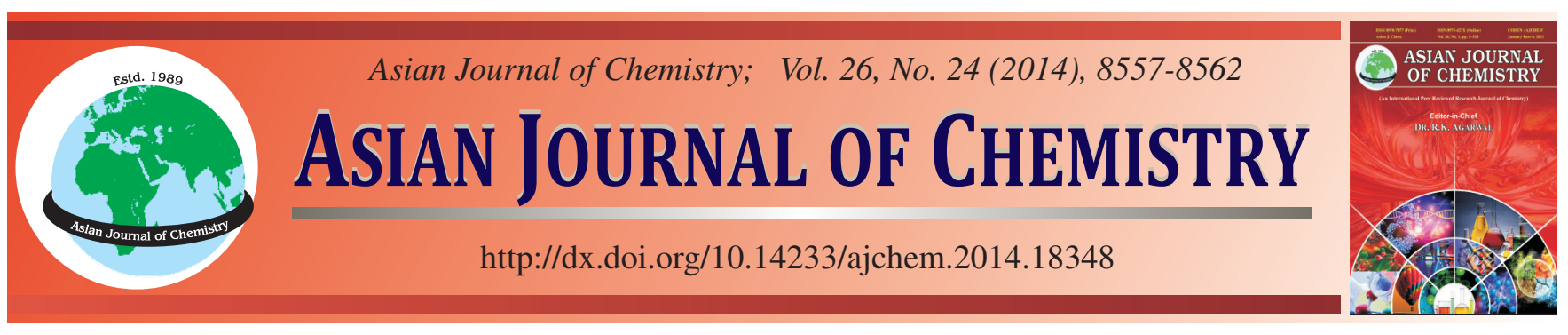

\title{
Physical Properties of Aqueous Mixtures of Acetamide-LiCl Eutectic Ionic Liquids as a Function of Temperature and Composition
}

\author{
BAOYOU LIU* and YARU LiU
}

Pollution Prevention Biotechnology Laboratory of Hebei Province, College of Environmental Science and Engineering, Hebei University of Science and Technology, Shijiazhuang, Hebei 050018, P.R. China

*Corresponding author: Fax: +86 311 81668429; Tel: +86 31181668435; E-mail: 1by7150@ sina.com

\begin{abstract}
The density, conductivity and viscosity of aqueous solutions of acetamide- $\mathrm{LiCl}$ eutectic ionic liquid were investigated at atmospheric pressure and temperatures from (303.15 to 343.15$) \mathrm{K}$ and within the whole composition range. The density values decrease linearly with the increase of the mass content of water and the data decrease with increasing temperature. The mole volume $\left(\mathrm{V}_{\mathrm{m}}\right)$ values were calculated from the experimental results. The perfect linear relationship between the $\mathrm{V}_{\mathrm{m}}$ values and the mole fraction of water indicates that the studied mixtures are ideal solution. The viscosity values decrease sharply with the increase of the mass fraction of water in ionic liquid rich region and then tend to decrease gently in water rich region. The relationship between reciprocal of viscosity $(1 / \eta)$ and the mass fraction of water can be well fitted with a second-order polynomial equation. With the increase mole fraction of water, the conductivity values of the solution increase gradually first and then decrease dramatically and the highest conductivity values appear at about 0.940-0.958 mole fraction of water. The relationship between the conductivity and the mole fraction of water can be well described by a Castell-Amis equation.
\end{abstract}

Keywords: Acetamide-LiCl, Eutectic ionic liquid, Water, property.

\section{INTRODUCTION}

Eutectic ionic liquid (EIL), also called deep eutectic solvent (DES) or ionic liquid analogue (ILA), is a type of ionic solvent prepared from salts and donor molecules ${ }^{1}$. In 2003, the deep eutectic phenomenon was first described for a mixture of an organic salt-choline chloride (2-hydroxyethyltrimethylammonium chloride) and a hydrogen bond donor compoundurea (CHCl:Urea) in a 1:2 mole ratio by Abbott et al. ${ }^{2}$, the melting point of the eutectic mixture is $12{ }^{\circ} \mathrm{C}$, which is much lower than either of the individual components. Compared with traditional ionic liquids, this eutectic ionic liquid is low-toxic, easily prepared from industrial bulk materials and sometimes biodegradable, which make it more and more attractive in the area of electrochemistry, material preparation, organic synthesis and isolation process. Except for organic salts, inorganic metal salts (or their hydrate) were confirmed to be effective components of eutectic ionic liquid ${ }^{3}$ and the hydrogen bond donors can also be selected from amines ${ }^{4}$, carboxylic acids ${ }^{5}$, amides $^{6}$, alcohol ${ }^{3}$ or phenol $^{3}$. Among which, the acetamide based eutectic ionic liquids have received especial attention. Acetamide forms eutectic mixture with various compounds for its high solubility with a large number of organic or inorganic compounds ${ }^{7}$ and the physicochemical properties of acetamide based eutectics resemble that of the properties of water solution for the "water-like" acid-base properties of acetamide. Table-1 showed the acetamide-inorganic salts based binary or ternary melts which are liquid at room temperature, the high density than water, the high conductivity, the moderate viscosity and tunable liquid range provide these systems kinship to the traditional room temperature ionic liquids.

It is firmly believed that the exquisite acetamide based eutectic ionic liquids, with the mutual properties of water and ionic liquids, must have broad application value as green solvents in reaction and separation engineering other than electrochemistry field ${ }^{16}$. Our recent research interest has been focused on the high efficiency absorption of sulfur dioxide $\left(\mathrm{SO}_{2}\right)$ in ionic liquids ${ }^{8}$. In our study, several acetamide based eutectic ionic liquids, such as acetamide-KSCN, Acetamide$\mathrm{NH}_{4} \mathrm{SCN}$, acetamide- $\mathrm{NaSCN}$, acetamide- $\mathrm{ZnCl}_{2}$ and acetamide- $\mathrm{LiCl}$ were prepared and firstly used as absorbents in $\mathrm{SO}_{2}$ absorption. They were confirmed to be promising alternative $\mathrm{SO}_{2}$ absorbent, with the advantages of high efficiency, low cost and ease of recycle ${ }^{15,17}$. The indispensable disadvantage of pure eutectic ionic liquids is their high viscosity, which can be overcome by the adoption of binary mixtures with water $^{18}$. Due to the promising application prospect, it was necessary to characterize them, measure their physical 
TABLE-1

TYPICAL ACETAMIDE BASED EUTECTIC IONIC LIQUIDS AND THEIR PROPERTIES

\begin{tabular}{|c|c|c|c|c|c|c|}
\hline EILs & Composition & $\begin{array}{c}\rho\left(\mathrm{g} / \mathrm{cm}^{3}\right), \\
25^{\circ} \mathrm{C}\end{array}$ & $\begin{array}{l}\mathrm{mp} \\
\left({ }^{\circ} \mathrm{C}\right)\end{array}$ & $\begin{array}{l}\text { Viscosity } \\
\text { cp } 25^{\circ} \mathrm{C}\end{array}$ & $\begin{array}{c}\text { Conductivity } \\
25^{\circ} \mathrm{C}(\mathrm{ms} / \mathrm{cm})\end{array}$ & [Ref.] \\
\hline Acetamide: $\mathrm{ZnCl}_{2}$ & $4: 1 \mathrm{~mol} \mathrm{\%}$ & 1.36 & -16 & $\sim 500$ & 0.18 & 3 \\
\hline Acetamide:Urea:ammounium nitrate & $27.4: 28: 34.6$ wt $\%$ & 1.18 & 7.5 & 78 & 6.3 & 8 \\
\hline Acetamide: $\mathrm{LiPF}_{6}$ & $5.5: 1 \mathrm{~mol} \mathrm{\%}$ & - & -52 & $\sim 70^{c}$ & $\sim 1.2$ & 9 \\
\hline Acetamide: $\mathrm{Ca}\left(\mathrm{NO}_{3}\right)_{2} \cdot 4.37 \mathrm{H}_{2} \mathrm{O}$ & 0.7409:0.2591 mol \% & $1.35^{\mathrm{b}}$ & $<-20$ & 98.74 & 4.091 & 10 \\
\hline Acetamide:LiBETI & $4: 1 \mathrm{~mol} \%$ & - & -57 & 222.4 & $1.27\left(6: 1 \mathrm{~mol} \%, 30^{\circ} \mathrm{C}\right)$ & 11 \\
\hline Acetamide: $\mathrm{Mg}\left(\mathrm{ClO}_{4}\right)_{2}$ & 0.83:0.17 $\mathrm{mol} \mathrm{\%}$ & 1.36 & $-75^{\mathrm{a}}$ & 53 & $\sim 6$ & 12 \\
\hline Acetamide: $\mathrm{Zn}\left(\mathrm{ClO}_{4}\right)_{2}$ & 0.8:0.2 mol \% & - & $-78^{\mathrm{a}}$ & 54 & 6.3 & 13 \\
\hline Acetamide: $\mathrm{LiTf}_{2} \mathrm{~N}$ & $0.8: 0.2 \mathrm{~mol} \mathrm{\%}$ & & -67 & 99.56 & 1.07 & 14 \\
\hline Acetamide:KSCN & $0.75: 0.25 \mathrm{~mol} \mathrm{\%}$ & 1.207 & 5 & $84.2^{\mathrm{c}}$ & $3.11^{\mathrm{c}}$ & 15 \\
\hline
\end{tabular}

properties and summarize the changing rule for designing new eutectic ionic liquids and developing their application in the actual processes. Unfortunately, the properties of deep eutectic solvent and their aqueous solutions are rather scarce ${ }^{19-21}$, related work is still subject to a wide study. In this paper, the density, conductivity and viscosity of acetamide- $\mathrm{LiCl}$ itself and its aqueous solutions were systematically discussed, at atmospheric pressure and temperatures from (303.15 to 343.15) K.

\section{EXPERIMENTAL}

Acetamide/LiCl eutectic ionic liquids were prepared according to literature method ${ }^{15}$. Acetamide and $\mathrm{LiCl}$ with the minimum content of $98.5 \%, 99.0 \%$, respectively, were purchased from Modern Instruments Chemical Reagents co., LTD, Shijiazhuang, China. Ultrapure water (with a conductivity $\leq 0.1 \mathrm{us} / \mathrm{cm}$ at $298.15 \mathrm{~K}$ ) was used and prepared in our lab using UPH-IV-10T ultrapure water Purifier System (Chengdu Ultrapure Science and Tecnnology co., LTD). The water content of pure eutectic ionic liquid was less than $0.1 \%$ (determined by Karl Fischer titration within $\pm 3 \%$ accuracy). The eutectic ionic liquid solutions were prepared by mixing accurately weighed eutectic ionic liquid and water at room temperature. The density, viscosity and conductivity of the eutectic ionic liquids were measured in a water bath with a temperature control accuracy of $\pm 0.01 \mathrm{~K}$. The density was determined by pycnometer method and the pycnometer was calibrated by anhydrous ethanol or water. The weight was measured by an analysis balance with $\pm 0.0001 \mathrm{~g}$ accuracy (Shanghai Precision and Scientific Sky Beautiful Instrument Co. LTD). The conductivity was measured by DDS-11A conductivity detector (Leici Xinjing instrument limited company, Shanghai, China). The standard $\mathrm{KCl}$ solution with $\mathrm{c}=0.01 \mathrm{~mol} \mathrm{~L}^{-1}$ was used for calibrating the conductivity detector. The viscosity was detected by Pinkevitch method according to GB/T10247-2008. Each measurement was done in at least 3 runs and the average value was calculated for the further study. The density and viscosity of pure water used in this study were taken from literature ${ }^{15}$. Uncertainties of density, viscosity and conductivity were \pm $0.001, \pm 0.2$ and $\pm 0.2 \%$, respectively.

\section{RESULTS AND DISCUSSION}

Density of acetamide- $\mathrm{LiCl}$ (3:1) aqueous solution: The densities were determined at atmospheric pressure and over the temperature range from 303.15 to $343.15 \mathrm{~K}$. The results were listed in Table-2 and more visually presented in Fig. 1. It can be seen from Fig. 1 that at the same water proportion, the density values always decrease with an increase of temperature. While at the same temperature, the density values decrease with the increase of the mass content of water. This means the physical properties of eutectic ionic liquids can be adjusted by adding a certain amount of water to meet the special application for the hydrophilic eutectic ionic liquids. From the experimental density data, the molecular volume $\mathrm{V}_{\mathrm{m}}$ of acetamide- $\mathrm{LiCl}$ (3:1) aqueous solutions at several temperatures were calculated from the density data by eqn. 1 ; where $\mathrm{M}_{1}$ and $\mathrm{M}_{2}$ are the molar mass of water and the eutectic ionic liquid, $\mathrm{X}_{1}$ is the molar fraction of water in the mixture. $\rho$ is the density of the binary mixtures. As is shown in Table-3 and Fig. 2, molar volume $\mathrm{V}_{\mathrm{m}}$ depends linearly with the molar fraction of water in the mixtures (eqn. 2), the fitted parameters of eqn. 2 and the correlation coefficients were listed in Table-4. The gradients increase with the increase of temperature, which reflected that $\mathrm{V}_{\mathrm{m}}$ is more sensitive at elevated temperature. The perfect linear relationship between $\mathrm{V}_{\mathrm{m}}$ and the mole fraction of water indicates the studied mixtures are ideal solution; similar results have been described for imidazolium ionic liquids by Wang et al. ${ }^{22}$.

$$
\begin{aligned}
& V_{m}=\frac{x_{1} M_{1}+\left(1-x_{1}\right) M_{2}}{\rho} \\
& V_{m}=a+b X
\end{aligned}
$$

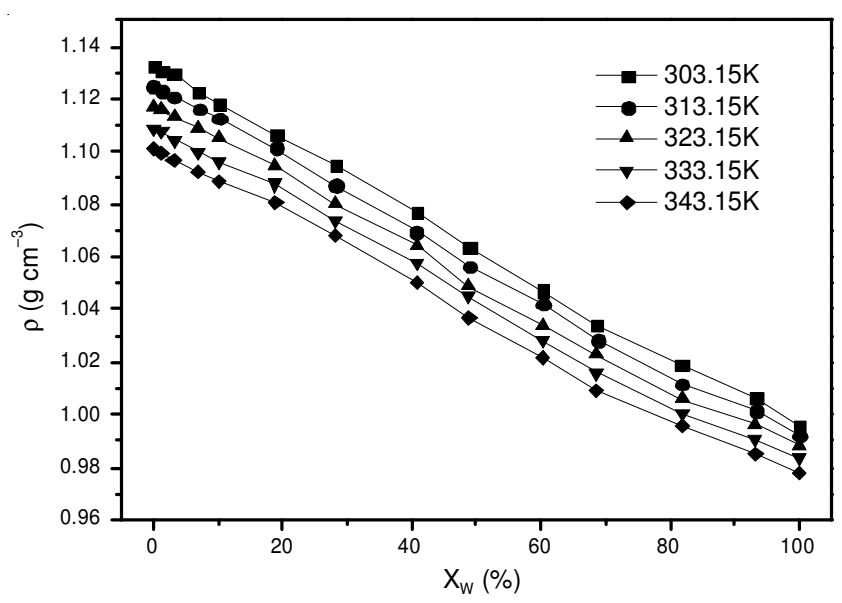

Fig. 1. Density of [water (1) + [acetamide-LiCl] (2)] mixtures at different mass fraction of water 


\begin{tabular}{|c|c|c|c|c|c|c|}
\hline \multicolumn{7}{|c|}{ DENSITY $(\rho)$ OF $[$ WABALR $(1)+[$ ACETAMIDE-LiCl $](2)]$} \\
\hline $\begin{array}{l}\text { Mass fraction of } \\
\text { water in mixture }\end{array}$ & $\begin{array}{l}\text { Mole fraction of } \\
\text { water in mixture }\end{array}$ & $303.15 \mathrm{~K}$ & $313.15 \mathrm{~K}$ & $323.15 \mathrm{~K}$ & $333.15 \mathrm{~K}$ & $343.15 \mathrm{~K}$ \\
\hline 0.00 & 0.000 & 1.1321 & 1.1248 & 1.1171 & 1.1089 & 1.1010 \\
\hline 1.33 & 0.122 & 1.1306 & 1.1233 & 1.1158 & 1.1076 & 1.0997 \\
\hline 3.20 & 0.255 & 1.1294 & 1.1208 & 1.1131 & 1.1044 & 1.0968 \\
\hline 7.00 & 0.438 & 1.1225 & 1.1163 & 1.1092 & 1.1001 & 1.0926 \\
\hline 10.17 & 0.539 & 1.1184 & 1.1127 & 1.1050 & 1.0962 & 1.0883 \\
\hline 18.98 & 0.708 & 1.1068 & 1.1012 & 1.0945 & 1.0876 & 1.0803 \\
\hline 28.24 & 0.803 & 1.0949 & 1.0871 & 1.0801 & 1.0736 & 1.0677 \\
\hline 40.80 & 0.877 & 1.0770 & 1.0698 & 1.0643 & 1.0578 & 1.0504 \\
\hline 48.90 & 0.908 & 1.0636 & 1.0564 & 1.0488 & 1.0450 & 1.0366 \\
\hline 60.35 & 0.940 & 1.0470 & 1.0422 & 1.0337 & 1.0281 & 1.0216 \\
\hline 68.70 & 0.958 & 1.0339 & 1.0286 & 1.0228 & 1.0160 & 1.0089 \\
\hline 81.90 & 0.979 & 1.0191 & 1.0118 & 1.0059 & 1.0006 & 0.9957 \\
\hline 93.30 & 0.993 & 1.0066 & 1.0017 & 0.9962 & 0.9908 & 0.9850 \\
\hline 100.00 & 1.000 & 0.9957 & 0.9922 & 0.9881 & 0.9832 & 0.9778 \\
\hline
\end{tabular}

TABLE-3

MOLAR VOLUME $\left(\mathrm{V}_{\mathrm{m}}\right)$ OF [WATER (1) + [ACETAMIDE-LiCl] (2)] MIXTURES AT SEVERAL TEMPERATURES

\begin{tabular}{|c|c|c|c|c|c|}
\hline Mole fraction of water in mixture & $303.15 \mathrm{~K}$ & $313.15 \mathrm{~K}$ & $323.15 \mathrm{~K}$ & $333.15 \mathrm{~K}$ & $343.15 \mathrm{~K}$ \\
\hline 0.000 & 164.508 & 165.576 & 166.717 & 167.950 & 169.155 \\
\hline 0.122 & 146.528 & 147.481 & 148.472 & 149.571 & 150.646 \\
\hline 0.255 & 126.963 & 127.941 & 128.821 & 129.837 & 130.731 \\
\hline 0.438 & 100.332 & 100.890 & 101.539 & 102.374 & 103.075 \\
\hline 0.539 & 85.412 & 85.852 & 86.443 & 87.137 & 87.777 \\
\hline 0.708 & 60.698 & 61.002 & 61.379 & 61.765 & 62.183 \\
\hline 0.803 & 46.773 & 47.110 & 47.417 & 47.700 & 47.964 \\
\hline 0.877 & 35.953 & 36.193 & 36.379 & 36.603 & 36.862 \\
\hline 0.908 & 31.458 & 31.672 & 31.902 & 32.018 & 32.277 \\
\hline 0.940 & 26.806 & 26.930 & 27.151 & 27.299 & 27.475 \\
\hline 0.958 & 24.293 & 24.416 & 24.557 & 24.719 & 24.895 \\
\hline 0.979 & 21.133 & 21.286 & 21.409 & 21.522 & 21.629 \\
\hline 0.993 & 19.049 & 19.142 & 19.249 & 19.354 & 19.468 \\
\hline 1.000 & 18.094 & 18.158 & 18.233 & 18.324 & 18.425 \\
\hline
\end{tabular}

TABLE-4

FITTED PARAMETERS OF EQUATION 2 AND R ${ }^{2}$ FOR MOLAR VOLUME $\left(\mathrm{V}_{\mathrm{m}}\right)$ OF (WATER (1) + (ACETAMIDE-LiCl)(2)) MIXTURES AT SEVERAL TEMPERATURES

\begin{tabular}{|c|c|c|c|c|c|}
\hline & $303.15 \mathrm{~K}$ & $313.15 \mathrm{~K}$ & $323.15 \mathrm{~K}$ & $333.15 \mathrm{~K}$ & $343.15 \mathrm{~K}$ \\
\hline $\mathrm{a}$ & 164.39 & 165.46 & 166.59 & 167.87 & 169.07 \\
\hline $\mathrm{b}$ & -146.37 & -147.36 & -148.38 & -149.58 & -150.67 \\
\hline $\mathrm{R}^{2}$ & 1 & 1 & 1 & 1 & 1 \\
\hline
\end{tabular}

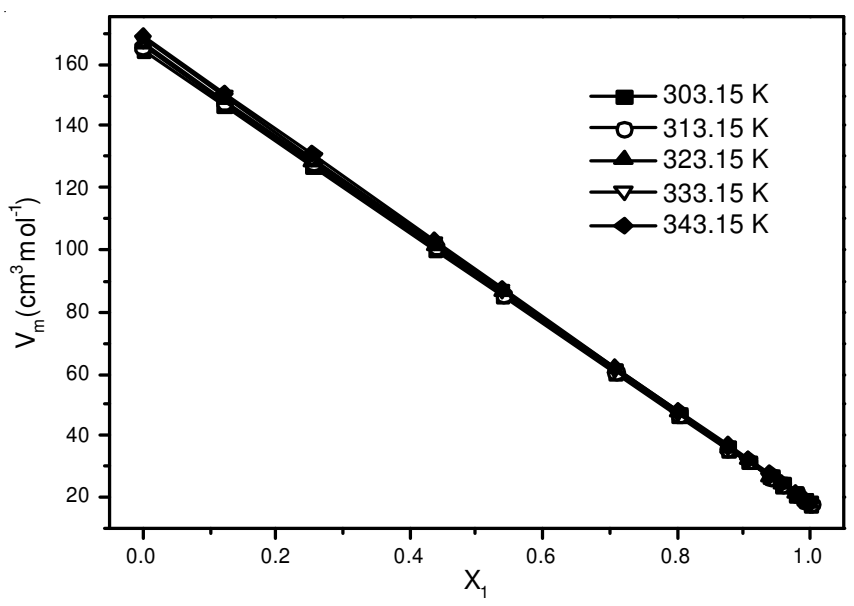

Fig. 2. Plot of molar volume $\left(V_{m}\right)$ obtained from experimental density $(\rho)$ against mole fraction of water for (water $(1)+($ acetamide- $\mathrm{LiCl})$ (2)) mixtures at several temperatures
Viscosity of acetamide-LiCl aqueous solution: The viscosity of binary mixtures of water (1) + [acetamide-LiCl] (2)] at several temperatures were detected and the results were given in Table-5. It can be seen that the viscosity of pure acetamide- $\mathrm{LiCl}$ is rather high, the data is about dozens of times of those data for pure $\mathrm{BMImBF}_{4}$ (cp) or $\mathrm{BMImPF}_{6}$ (cp), at $303.15 \mathrm{~K}$ the viscosity values of $\mathrm{BMImBF}_{4}$ and $\mathrm{BMImPF}_{6}$ are $65.2 \mathrm{cp}$ and $172.8 \mathrm{cp}$ separately ${ }^{23}$. With the addition of water, whose viscosity is $0.80 \mathrm{cp}$ at $303.15 \mathrm{~K}$, the viscosity values decrease sharply with the increase of the mass fraction of water in ionic liquid-rich region and then tend to decrease gently in water rich region. The viscosity of an eutectic ionic liquid can be correlated with the molecular-ion interaction. The experimental results indicate that a small addition of water is enough to drastically change the strong intermolecular interactions and to affect the dependence between viscosity and the mass fraction of water. It can also be seen from Table- 5 that the viscosity 
TABLE-5

VISCOSITY $(\eta)$ OF THE BINARY MIXTURE OF [WATER (1) + [ACETAMIDE-LiCl] (2)] AT DIFFERENT TEMPERATURES

\begin{tabular}{|c|c|c|c|c|c|}
\hline Mass fraction of water in mixture & $303.15 \mathrm{~K}$ & $313.15 \mathrm{~K}$ & $323.15 \mathrm{~K}$ & $333.15 \mathrm{~K}$ & $343.15 \mathrm{~K}$ \\
\hline 0.00 & 7692.31 & 2166.67 & 885.55 & 410.17 & 240.12 \\
\hline 1.33 & 2726.60 & 1040.03 & 420.34 & 254.19 & 138.02 \\
\hline 3.20 & 1202.06 & 535.01 & 239.16 & 130.55 & 73.17 \\
\hline 7.00 & 534.21 & 260.44 & 146.95 & 83.37 & 49.75 \\
\hline 10.17 & 297.25 & 132.27 & 75.32 & 39.93 & 26.72 \\
\hline 18.98 & 61.14 & 27.30 & 17.46 & 11.70 & 8.27 \\
\hline 28.24 & 12.79 & 8.89 & 6.53 & 4.80 & 3.64 \\
\hline 48.90 & 3.81 & 2.85 & 2.21 & 1.81 & 1.62 \\
\hline 60.35 & 2.55 & 2.00 & 1.36 & 1.11 & 1.10 \\
\hline 68.70 & 1.79 & 1.42 & 1.11 & 0.86 & 0.87 \\
\hline 81.90 & 1.11 & 0.89 & 1.10 & 0.63 & 0.65 \\
\hline 93.30 & 0.89 & 0.72 & 0.62 & 0.52 & 0.55 \\
\hline 100.00 & 0.80 & 0.65 & 0.55 & 0.47 & 0.40 \\
\hline
\end{tabular}

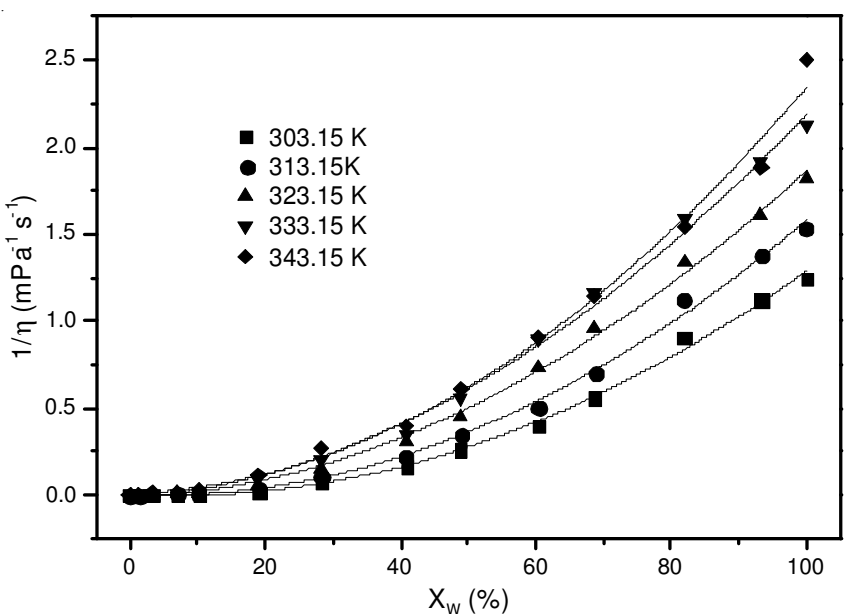

Fig. 3. Plot of reciprocal viscosity $1 / \eta$ against mass fraction of water for (water (1) + (acetamide-LiCl) (2)) mixtures at different temperatures

values decrease with the increase of temperature but they also seem to be less affected by the presence of water due to the weakening of the $\mathrm{H}$-bond interactions. The relationship between reciprocal of viscosity $(1 / \eta)$ (Table-6) and the mass fraction of water can be well fitted with a second-order polynomial equation (eqn. 3), the curve was shown in Fig. 3. Where $\eta$ is the viscosity of the mixture and A, B, C were fitted parameters and $\mathrm{x}$ is the mass fraction of water in mixture. Fitted parameters of eqn. 3 and $\mathrm{R}^{2}$ had been listed in Table-7. With the empirical equation, the viscosity value of a mixture can be accurately predicted and the water content can be calculated by the viscosity detection.

$$
1 / \eta=A x^{2}+B x+C
$$

Conductivity of acetamide- $\mathrm{LiCl}$ aqueous solution: The conductivity of the mixtures of [water (1) + [acetamide-LiCl] (2)] at several temperatures are given in Table- 8 and more visually presented in Fig. 4. With the increase mole fraction of water, the conductivity of aqueous solutions of acetamide$\mathrm{LiCl}$ (3:1) increase gradually first and then decrease dramatically, similar results had been observed by Vila et $a .^{24}$ and Zhu et $a .^{25}$. They studied the typical imidazolium based ionic liquids. The highest conductivity values appear in the vicinity about 0.940-0.958 mole fraction of water. The maximum conductivity of $74.94 \mathrm{mS} / \mathrm{cm}$ at the 0.940 mole fraction of water were observed, which is higher than those of aqueous solution of $\mathrm{BMImBF}_{4}$, whose highest conductivity is 37.81 $\mathrm{mS} / \mathrm{cm}$ at the 0.9007 mole fraction of water. On the other hand, the increase in the conductivity from the value of the pure EIl to the value at the maximum is several hundred times for [water (1) + [acetamide-LiCl] (2)], while only 15 times for $\mathrm{BMImBF}_{4}{ }^{25}$. The wide range of electrical conductivity means broad application prospects of these eutectic ionic liquids. The conductivity of eutectic ionic liquid aqueous solutions increases with

\begin{tabular}{|c|c|c|c|c|c|}
\hline \multicolumn{6}{|c|}{ 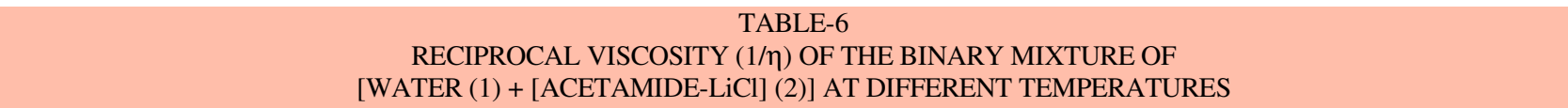 } \\
\hline Mass fraction of water in mixture & $303.15 \mathrm{~K}$ & $313.15 \mathrm{~K}$ & $323.15 \mathrm{~K}$ & $333.15 \mathrm{~K}$ & $343.15 \mathrm{~K}$ \\
\hline 0.00 & 0.0001 & 0.0005 & 0.0011 & 0.0024 & 0.0042 \\
\hline 1.33 & 0.0004 & 0.0010 & 0.0024 & 0.0039 & 0.0072 \\
\hline 3.20 & 0.0008 & 0.0019 & 0.0042 & 0.0077 & 0.0137 \\
\hline 7.00 & 0.0019 & 0.0038 & 0.0068 & 0.0120 & 0.0189 \\
\hline 18.98 & 0.0164 & 0.0366 & 0.0573 & 0.0854 & 0.1210 \\
\hline 28.24 & 0.0782 & 0.1125 & 0.1532 & 0.2084 & 0.2745 \\
\hline 40.80 & 0.1659 & 0.2253 & 0.3026 & 0.3499 & 0.3958 \\
\hline 48.90 & 0.2623 & 0.3505 & 0.4525 & 0.5532 & 0.6158 \\
\hline 60.35 & 0.3927 & 0.5010 & 0.7353 & 0.9009 & 0.9091 \\
\hline 68.70 & 0.5589 & 0.7047 & 0.9638 & 1.1609 & 1.1508 \\
\hline 81.90 & 0.9026 & 1.1211 & 1.3416 & 1.5813 & 1.5373 \\
\hline 100.00 & 1.2500 & 1.5385 & 1.8182 & 2.1277 & 2.5000 \\
\hline
\end{tabular}




\begin{tabular}{cccccc}
\hline & \multicolumn{5}{c}{ TABLE-7 } \\
& \multicolumn{5}{c}{ FITTED PARAMETERS OF EQUATION 3 AND R ${ }^{2}$ FOR RECIPROCAL VISCOSITY $(1 / \eta)$} \\
& OF (WATER (1) + (ACETAMIDE- LiCl) $(2))$ MIXTURES AT DIFFERENT TEMPERATURES \\
\hline $\mathrm{T}(\mathrm{K})$ & $303.15 \mathrm{~K}$ & $313.15 \mathrm{~K}$ & $323.15 \mathrm{~K}$ & $333.15 \mathrm{~K}$ & $343.15 \mathrm{~K}$ \\
\hline $\mathrm{A}\left(10^{-3}\right)$ & -1.85 & -1.32 & 1.92 & 3.2 & 1.04 \\
$\mathrm{~B}\left(10^{-4}\right)$ & 1.47 & 1.71 & 1.69 & 1.89 & 2.23 \\
$\mathrm{C}\left(10^{-3}\right)$ & 3.26 & 2.23 & -15.8 & -18.63 & 11.62 \\
$\mathrm{R}^{2}$ & 0.997 & 0.997 & 0.997 & 0.996 & 0.992 \\
\hline
\end{tabular}

\begin{tabular}{|c|c|c|c|c|c|}
\hline \multicolumn{6}{|c|}{$\begin{array}{r}\text { TABLE-8 } \\
\text { CONDUCTIVITY OF THE BINARY MIXTURE OF [WATER (1) + [A }\end{array}$} \\
\hline Mole fraction of water in mixture & $303.15 \mathrm{~K}$ & $313.15 \mathrm{~K}$ & $323.15 \mathrm{~K}$ & $333.15 \mathrm{~K}$ & $343.15 \mathrm{~K}$ \\
\hline 0.000 & 0.09 & 0.20 & 0.46 & 0.82 & 1.26 \\
\hline 0.122 & 0.13 & 0.31 & 0.65 & 1.17 & 1.84 \\
\hline 0.255 & 0.21 & 0.48 & 0.92 & 1.69 & 2.87 \\
\hline 0.438 & 0.57 & 1.16 & 2.05 & 3.33 & 4.96 \\
\hline 0.539 & 1.17 & 2.18 & 3.51 & 5.33 & 7.73 \\
\hline 0.708 & 4.92 & 7.42 & 10.55 & 12.74 & 16.05 \\
\hline 0.803 & 13.45 & 18.55 & 24.87 & 31.39 & 38.25 \\
\hline 0.877 & 25.25 & 32.48 & 40.42 & 48.60 & 56.88 \\
\hline 0.908 & 32.34 & 41.84 & 50.16 & 59.15 & 68.04 \\
\hline 0.940 & 39.15 & 47.66 & 56.88 & 65.72 & 74.94 \\
\hline 0.958 & 40.33 & 48.18 & 56.41 & 64.87 & 73.38 \\
\hline 0.979 & 32.43 & 36.31 & 39.50 & 42.90 & 46.20 \\
\hline 0.993 & 22.88 & 27.47 & 31.68 & 35.55 & 39.13 \\
\hline 1.000 & 0.00 & 0.00 & 0.00 & 0.00 & 0.00 \\
\hline
\end{tabular}

\begin{tabular}{cccccc}
\multicolumn{7}{c}{ TABLE-9 } \\
\multicolumn{7}{c}{$\begin{array}{l}\text { FITTED PARAMETERS OF EQUATION 4 AND } \sigma \text { FOR CONDUCTIVITY }(\kappa) \text { OF } \\
\text { (WATER (1) + (ACETAMIDE- LiCl) }\end{array}$} \\
& $(2))$ MIXTURES AT DIFFERENT TEMPERATURES & \\
\hline Temperatures $(\mathrm{k})$ & $303.15 \mathrm{~K}$ & $313.15 \mathrm{~K}$ & $323.15 \mathrm{~K}$ & $333.15 \mathrm{~K}$ & $343.15 \mathrm{~K}$ \\
\hline $\mathrm{k}_{\max }$ & 40.33 & 48.18 & 56.88 & 65.72 & 74.94 \\
$\mathrm{x}_{\max }$ & 0.964 & 0.964 & 0.949 & 0.949 & 0.949 \\
$\mathrm{a}$ & 0.509 & 0.444 & 0.642 & 0.643 & 0.631 \\
$\mathrm{~b}$ & 8.239 & 6.764 & 5.270 & 6.851 & 1.279 \\
$\sigma$ & 2.037 & 3.407 & 2.331 & 3.369 & 6.491 \\
\hline
\end{tabular}

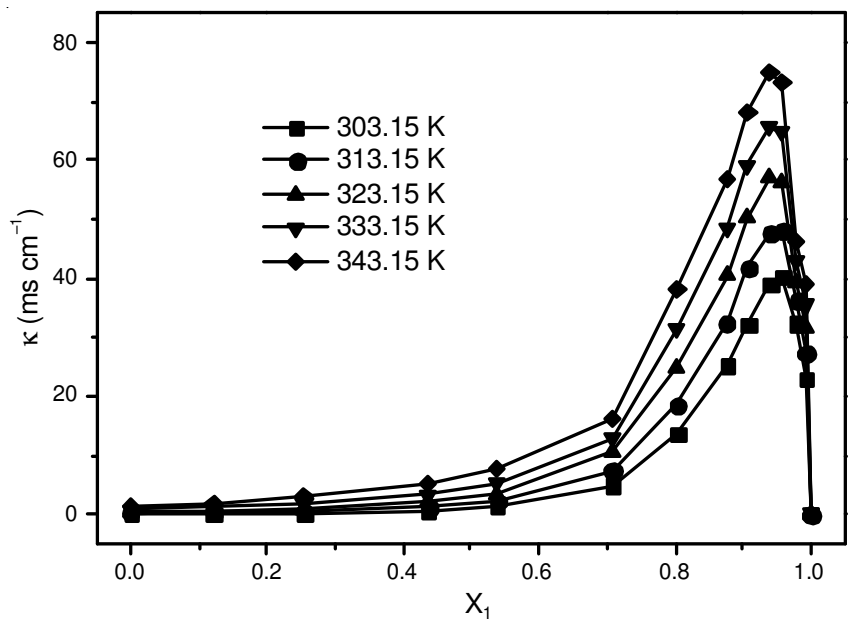

Fig. 4. Plot of conductivity $(\kappa)$ against mole fraction for the system of (water (1) + (acetamide-LiCl) (2)) at different temperatures

an increase of temperature at whole concentration ranged, that is because the viscosity of the eutectic ionic liquid decreases sharply and the ions move faster with increasing temperature. The relationship between the conductivity and the mole fraction of water can be well described by a Castell-Amis equation (eqn. 4). Where $\kappa$ is the electrical conductivity, $\kappa_{\max }$ is the maximum value of the electrical conductivity of the solution at the mole fraction scale $\mathrm{x}_{\max }, \mathrm{x}_{1}$ is the mole fraction of water, $\mathrm{a}$ and $\mathrm{b}$ are fitting constants. The obtained parameters of $\kappa_{\max }$, $\mathrm{x}_{\max }, \mathrm{a}$ and $\mathrm{b}$ are summarized in Table- 9 together with the standard deviations (s, calculated according to eqn. 5).

$$
\begin{gathered}
\kappa=\kappa_{\max }\left(\frac{1-\mathrm{x}_{1}}{1-\mathrm{x}_{\max }}\right)^{\mathrm{a}} \exp \left[\mathrm{b}\left(\mathrm{x}_{\max }-\mathrm{x}_{1}\right)^{2}-\frac{\mathrm{a}}{1-\mathrm{x}_{\max }}\left(\mathrm{x}_{\max }-\mathrm{x}_{1}\right)\right] \\
\sigma=\left[\sum_{1}^{\mathrm{n}_{\text {dat }}}\left(\mathrm{z}_{\text {exp }}-\mathrm{z}_{\text {cal }}\right)^{2} / \mathrm{n}_{\text {dat }}\right]^{1 / 2}
\end{gathered}
$$

Here $\mathrm{Z}_{\text {exp }}, \mathrm{Z}_{\text {cal }}$ and $\mathrm{n}_{\text {dat }}$ present the experimental value, calculated value by eqn. 4 and the number of experimental data, respectively.

\section{Conclusion}

The effects of water on the density, viscosity and conductivity of acetamide- $\mathrm{LiCl}$ eutectic ionic liquid were reported at temperature range from 303.15 to $343.15 \mathrm{~K}$. The density and viscosity values decrease monotonically when the mole fraction of water increases in the whole composition range and the data decrease with increase of temperature. From the experimental values, the molecular volume $\mathrm{V}_{\mathrm{m}}$ of acetamide- 
$\mathrm{LiCl}$ (3:1) solution was calculated and the relationship between $\mathrm{V}_{\mathrm{m}}$ and the mole fraction of water can be described by a linear equation. The dependence of reciprocal of viscosity $(1 / \eta)$ on the mass fraction of water has been fitted with a second-order polynomial equation. The relationship between the conductivity and the mole fraction of water can be described by a Castell-Amis equation. It is expected that the data and the obtained equation will be useful for the application of eutectic ionic liquid in the industrial process.

\section{ACKNOWLEDGEMENTS}

This work was financially supported by University Youth Fund of Hebei Province Department of Education (2012007) and Environment Engineering Key Subject Construction Project of Hebei Province.

\section{REFERENCES}

1. Q. Zhang, K. De Oliveira Vigier, S. Royer and F. Jérôme, Chem. Soc. Rev., 41, 7108 (2012).

2. A.P. Abbott, G. Capper, D.L. Davies, R.K. Rasheed and V. Tambyrajah, Chem. Commun., 70 (2003).

3. A.P. Abbott, J.C. Barron, K.S. Ryder and D. Wilson, Chem. Eur. J., 13, 6495 (2007).

4. Y. Hou, Y. Gu, S. Zhang, F. Yang, H. Ding and Y. Shan, J. Mol. Liq., 143, 154 (2008).

5. A.P. Abbott, D. Boothby, G. Capper, D.L. Davies and R.K. Rasheed, J. Am. Chem. Soc., 126, 9142 (2004)

6. R. Chen, F. Wu, B. Xu, L. Li, X. Qiu and S. Chen, J. Electrochem. Soc., 154, A703 (2007).

7. G. Berchiesi, G.G. Lobbia, V. Bartocci and G. Vitali, Thermochim. Acta, 70, 317 (1983)
8. V.S. Dilimon, N.S. Venkata Narayanan and S. Sampath, Electrochim. Acta, 55, 5930 (2010).

9. Q. Li, X. Zuo, J. Liu, X. Xiao, D. Shu and J. Nan, Electrochim. Acta, 58, 330 (2011).

10. S. Mahiuddin, J. Chem. Eng. Data, 41, 231 (1996).

11. Y. Hu, Z. Wang, X. Huang and L. Chen, Solid State Ion., 175, 277 (2004).

12. N.S. Venkata Narayanan, B.V. Ashok Raj and S. Sampath, Electrochem. Commun., 11, 2027 (2009).

13. N.S. Venkata Narayanan, B.V. Ashok Raj and S. Sampath, J. Colloid Interf. Sci., 342, 505 (2010).

14. Y. Hu, H. Li, X. Huang and L. Chen, Electrochem. Commun., 6, 28 (2004)

15. B. Liu, F. Wei, J. Zhao and Y. Wang, RSC Adv., 3, 2470 (2013).

16. M.H. Chakrabarti, F.S. Mjalli, I.M. Al Nashef, M. Hashim, M.A. Hussain, L. Bahadori and C.T.J. Low, Renew. Sustain. Energy Rev., 30, 254 (2014).

17. J. Zhao, B. Liu and F. Wei, Environ. Sci. Technol., 37, 150 (2014).

18. K. Huang, J.-F. Lu, Y.-T. Wu, X.-B. Hu and Z.-B. Zhang, Chem. Eng. J., 215-216, 36 (2013).

19. K.R. Siongco, R.B. Leron and M.-H. Li, J. Chem. Thermodyn., 65, 65 (2013).

20. K.R. Siongco, R.B. Leron, A.R. Caparanga and M.-H. Li, Thermochim. Acta, 566, 50 (2013).

21. B. Liu, J. Zhao and F. Wei, J. Mol. Liq., 187, 309 (2013).

22. J.Y. Wang, H.C. Jiang, Y.M. Liu and Y.Q. Hu, J. Chem. Thermodyn., 43, 800 (2011).

23. L.C. Branco, J.N. Rosa, J.J. Moura Ramos and C.A.M. Afonso, Chem. Eur. J., 8, 3671 (2002).

24. J. Vila, P. Ginés, E. Rilo, O. Cabeza and L.M. Varela, Fluid Phase Equilib., 247, 32 (2006).

25. A.L. Zhu, J.J. Wang, L.J. Han and M.H. Fan, Chem. Eng. J., 147, 27 (2009).

26. M. Hou, Y. Xu, Y. Han, B. Chen, W. Zhang, Q. Ye and J. Sun, J. Mol. Liq., 178, 149 (2013). 